\title{
METÁFORAS NO-DUALES EN EL BUDISMO Y EL SUFISMO
}

\section{Fernando Mora Zahonero}

Recibido el 18/05/17. Aceptado el 05/07/17.

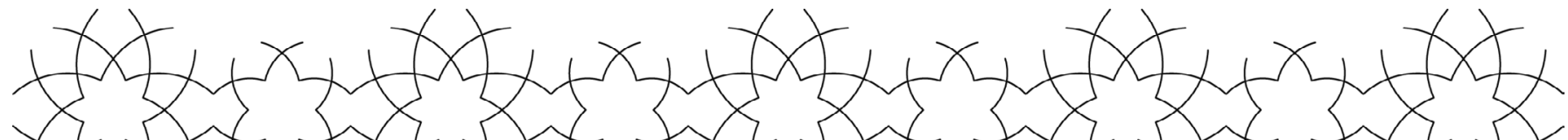

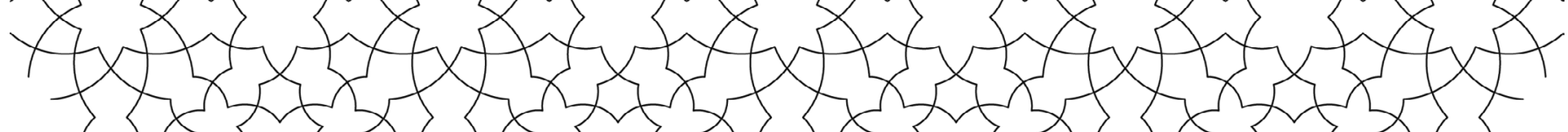

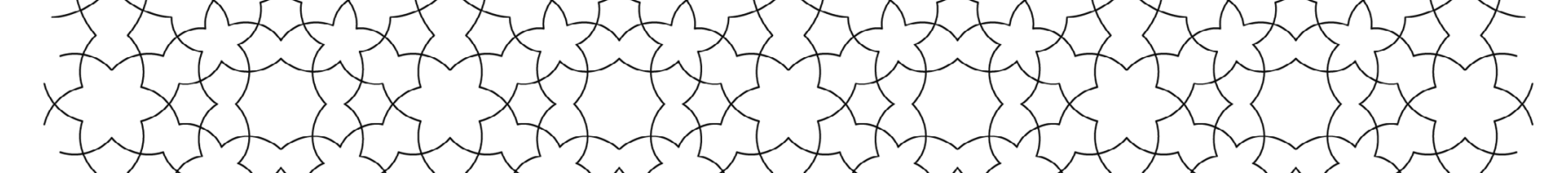

(t)
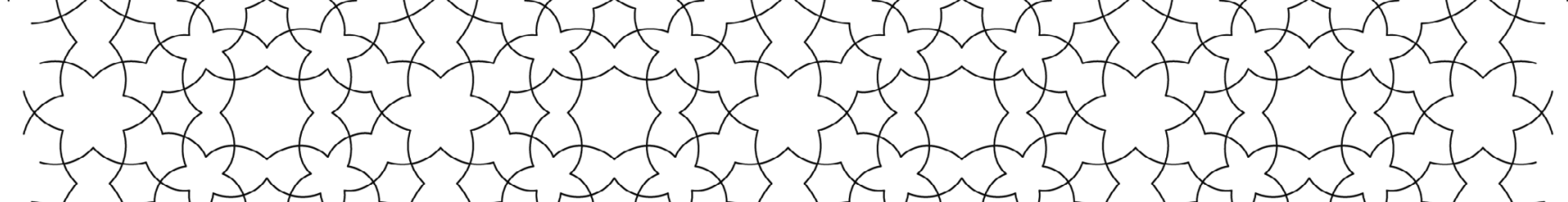

$+x_{2}$

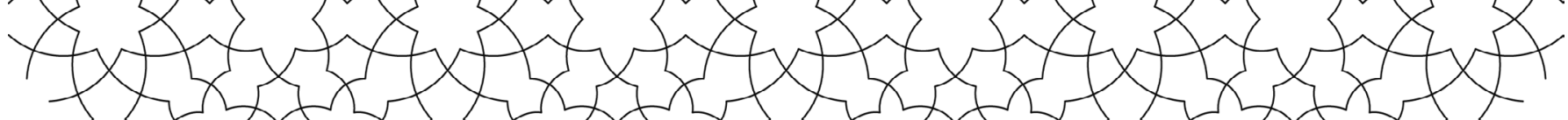

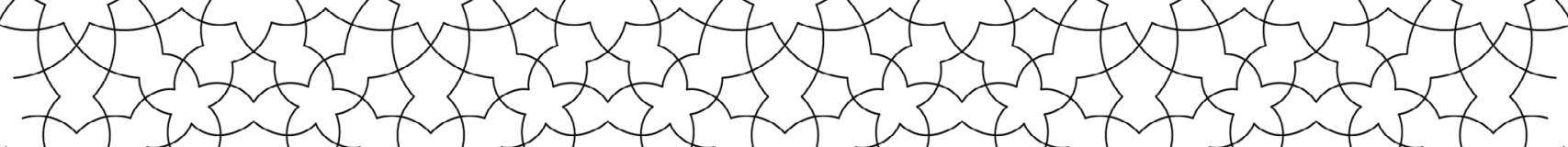

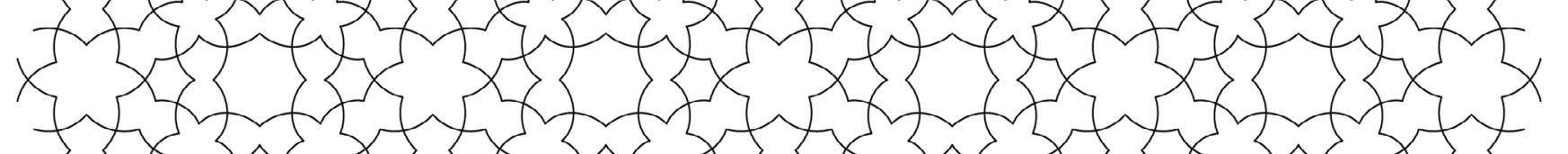

trat $7 \times x+5 \times x+2 \times x+2 \times x+2 \times 4$

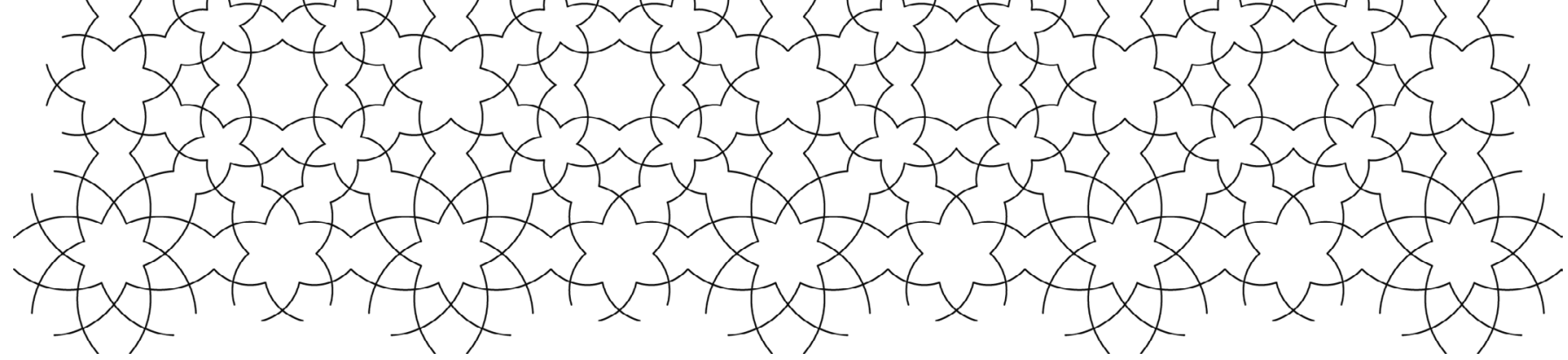


Si bien no resulta factible ni elegante comparar directamente las doctrinas de las tradiciones sufí y budista, pues se basan en presupuestos filosóficos muy alejados entre sí, puede que resulte más adecuado abordar el uso que hacen de determinadas imágenes, en ocasiones idénticas, que, como ocurre con todas las metáforas y alegorías, pueden mostrarnos aspectos de la estructura de la realidad que no somos capaces de captar por otros medios. No nos ocuparemos, por tanto, de posibles influencias históricas ni de hipotéticas líneas de comunicación entre budismo y sufismo, sino que lo que nos interesa subrayar es la eminente función pedagógica que cumple este tipo de imágenes en uno y otro sistema.

Lo más importante, en este caso, no es que las imágenes se expongan con un determinado contenido ideológico -budista, musulmán, cristiano o védico, por ejemplo-, sino el hecho de que los elementos que las conforman siempre mantienen entre sí la misma correspondencia estructural. Y es esa relación invariable lo que queremos destacar, ya que con independencia del distinto revestimiento conceptual, cultural o religioso con que se recubran, es algo que permanece constante en cada tradición. Así pues, el principal mensaje a descifrar en dichas imágenes no reside tanto en sus respectivos matices filosóficos o ideológicos como en la relación ontológica que pretenden mostrarnos.

Imágenes, por ejemplo, como las de la descomposición del rayo de luz en diferentes colores, el océano y las olas, o el espejo y los reflejos, reciben una formulación conceptual diferente en cada tradición, pero son utilizadas de manera muy similar para señalar lo que podemos definir, dependiendo del contexto de que se trate, como la relación existente entre realidad absoluta y realidad relativa, entre unidad y multiplicidad, entre la fuente invisible del ser y la existencia manifiesta, entre infinito y finitud, entre Dios y creación, entre iluminación e ignorancia, e incluso entre la mente en estado de quietud $-\mathrm{o}_{\text {carente de pensamientos }}^{-}$y la mente pensante o en movimiento.

Como escribe el psicólogo Ralph Metzner refiriéndose en concreto al proceso de elaboración de uno de sus libros, Las grandes metáforas de la tradición sagrada: «[...] mientras había literalmente cientos de métodos específicos de provocar la transformación psicoespiritual (métodos de yoga y psicoterapia en particular), parecía haber tan sólo más o menos una docena de metáforas que describían el proceso en sí, y que aparecían una y otra vez en la literatura universal [...] Dilucidando sobre estas estructuras subyacentes, las cuales han sido calificadas de arquetipos, estructuras profundas o imágenes primordiales, estamos descubriendo algo del lenguaje común de la humanidad. El lenguaje de los símbolos es el lenguaje común universal, el lenguaje que todos entendíamos antes de que hubiese la "confusión de lenguas". Es el lenguaje que todavía utilizamos y entendemos: en los sueños, en la poesía y el arte, en las visiones y en las voces que nos hablan de realidades no ordinarias, de lo sagrado, del misterio» ${ }^{1} \mathrm{Y}$, si bien Metzner aborda en su trabajo un amplio abanico de imágenes - como las del árbol, el fuego, la iluminación, etcétera-, también existen otras, como las recogidas en este capítulo, que también desempeñan funciones didácticas muy similares. 


\section{EL RAYO DE LUZ DESGOMPUESTO EN DIFERENTES COLORES}

Para ayudarnos a entender los aspectos transcendente e inmanente de la existencia (wuğūd) o de incomparabilidad (tanzīh) y similitud (tašbihh) divinas, el gran místico y santo Ibn 'Arabī recurre en diversas ocasiones a la analogía de la luz y su descomposición en los colores del espectro, donde la luz representa a la unidad de la existencia pura e incondicionada, mientras que la pluralidad de fenómenos y seres que pueblan el cosmos se compara a los colores en que se descompone, en presencia de las condiciones adecuadas, el rayo de luz básicamente incoloro.

En tanto que luz divina, la existencia absoluta comparte varias características con la luz física, ya que aporta, al igual que esta, el medio a través del cual son percibidos todos los colores, formas y objetos que pueblan nuestro universo, aunque ella misma es imperceptible, incolora y carente de forma. Y señala a este respecto el Šayh al-Akbar: «Aunque el wuğūd es incognoscible en sí mismo, se despliega a través de sus automanifestaciones. Así como la luz presenta diferentes modalidades de despliegue que denominamos "colores", el wry̆ŭd también tiene modalidades de autodespliegue a los que denominamos nombres, atributos o relaciones». ${ }^{2}$

Estas automanifestaciones - también llamadas teofanías o revelaciones divinas- son percibidas de acuerdo a la capacidad receptiva de cada ser. Y explica William C. Chittick que «nuestra percepción de las cosas en el wuğūd es análoga a lo que percibimos cuando la luz atraviesa un prisma; aunque hay muchos colores diferentes, percibimos tan sólo luz porque sólo la luz existe». ${ }^{3}$

Así pues, aunque contemplamos los colores como si estos fuesen independientes, tan sólo son refracciones de la misma luz original. Podemos afirmar, en consecuencia, la realidad de los colores sin rechazar por ello la presencia de la luz, ni mantener que cada color posee una existencia al margen de ella. El rojo, el azul o el amarillo existen únicamente gracias a la luz y aparecen cuando concurren las condiciones ópticas adecuadas. Expresado en términos ontológicos, todo lo que experimentamos en el cosmos, incluidos nosotros mismos, es inexistente en y por sí mismo, pero existente gracias a la luz del wuğūd de lo Real. Y, de modo parecido, cada color percibido en el plano físico carece de realidad independiente, pero existe a través de la presencia de la luz. Las criaturas no existen de manera

autónoma, pero sí con relación a lo Real; de ahí que el gran Šayh declare en varias ocasiones que el cosmos es y no es o que es Dios y no-Dios.

La misma imagen de la luz esencialmente incolora, aunque descompuesta en las tonalidades del arco iris, sirve al budismo para exponer la auténtica naturaleza de los fenómenos externos e internos, es decir, del mundo y el yo. Como ya hemos señalado, la refracción que experimenta la luz al atravesar un prisma da lugar a la aparición de los colores del espectro, que, si bien parecen separados del cristal, no son de hecho sino diferentes funciones de la propia naturaleza de este, es decir, del prisma que aporta las condiciones físicas propicias para que se descomponga el rayo de luz. De manera similar, aquello que percibimos como un mundo de fenómenos aparentemente externos no está 
$\vdots$

separado de la unidad fundamental de lo que es, ni de nuestra propia experiencia individual. Así pues, tanto Ibn 'Arabī como el budismo recurren a la imagen de la luz y su descomposición en los colores con la intención de señalar que unidad y multiplicidad, realidad y apariencia, son dos facetas interdependientes que mantienen entre sí un vínculo indestructible.

Sin embargo, a pesar de que la realidad absoluta y la realidad relativa se hallan en continua comunicación, la primera no se ve afectada por la actividad incesante de la segunda o, dicho de otro modo, la luz no experimenta modificación alguna debido a la presencia de los diferentes colores ni de las condiciones ópticas que la hacen refractarse. Por eso, sostiene también Ibn 'Arabī en uno de sus escritos: «De modo que declaramos que lo Real es demasiado exaltado para ser enturbiado por las propiedades cambiantes de las cosas posibles dentro de la entidad del wuğūd de lo Real. Dicho en otras palabras, lo Real en sí es demasiado sublime y exaltado para cambiar en sí mismo debido a las variaciones de estas propiedades. Decimos algo similar en el caso de un trozo de cristal coloreado en muchos tonos cuando lo atraviesa la luz. El rayo de luz se difunde en diversos colores debido a las propiedades de la coloración del cristal. Pero sabemos que la luz misma no ha sido coloreada por ninguno de esos colores, aun cuando la percepción de los sentidos presencia la coloración de la luz en diversos tonos. Por lo tanto, esa luz es demasiado exaltada en sí para aceptar la coloración en su propia esencia. Por el contrario, aunque somos testigos de que está libre de aquello, también sabemos que no puede ser percibida de ninguna otra manera». ${ }^{4}$

Por otra parte, la tradición dzogchen del budismo tibetano sostiene que, si bien una esfera de cristal carece de color, si acercamos a ella una tela roja, parecerá adquirir ese color; y si ponemos cerca una tela verde, se mostrará de color verde, y así sucesivamente. Y de igual modo que una bola de cristal parece adquirir las diversas tonalidades de los objetos ubicados cerca de ella, nuestro potencial espiritual más profundo, que es esencialmente ilimitado y carente de forma, se manifiesta bajo la apariencia de nuestro cuerpo, nuestra mente y nuestro entorno. Como declara el sufí al-Ǧunayd, sirviéndose de una metáfora similar, el agua siempre adquiere el color y la forma del recipiente que la contiene.

\section{EL OGÉANO Y LAS OLAS}

Y, a propósito de las propiedades del agua, la alegoría del mar y las olas también es compartida por los pensadores sufies y por diferentes sistemas orientales no islámicos - como budismo e hinduismo-, y puede ayudarnos a entender el esquema de base más común en el pensamiento oriental, a saber, que la realidad absoluta no está desconectada del plano fenoménico, y que unidad y multiplicidad son facetas indisociables la una de la otra. 
Haydar Āmulī, importante seguidor persa de la escuela akbarí, explica dicha comunicación indestructible entre realidad absoluta y relativa, entre unidad y multiplicidad, entre existencia pura e indiferenciada y existencia fenoménica limitada, recurriendo a la imagen del océano y las olas. Las olas no son más que las diferentes formas que asume el agua del océano y, en ese sentido, no pueden subsistir con independencia de este. Pero el mar tampoco podría ser lo que es en ausencia de las olas y corrientes que se mueven dentro de él porque, aunque nos parezca diferente en cada ola, su realidad es equiparable a la totalidad de sus olas y corrientes. El punto a subrayar en este caso es que, al igual que las olas no pueden existir sin el mar, este también es inseparable de las olas, lo que implica que la realidad profunda de la existencia es indisociable de su expresión fenoménica más superficial y viceversa. ${ }^{5}$ Y señala Haydar Āmulī:

«Sabe que la existencia absoluta, o Dios, es como un océano sin límites, mientras que las cosas determinadas e individuales son comparables a las corrientes y olas innumerables. De igual modo que las innumerables olas y corrientes no son sino el mar que se despliega en virtud de las formas que exige su propia perfección en tanto que agua y de las particularidades que posee como mar, así también las cosas existentes no son en su determinación sino el despliegue de la existencia absoluta bajo las formas requeridas por sus propias perfecciones esenciales, así como por las particularidades de sus articulaciones internas.

Además, desde cierta perspectiva, las olas y corrientes no son el mar pero, desde otro, son lo mismo que este. De hecho, las olas y corrientes son diferentes del mar en aquello que tienen de determinado y particular, pero no son diferentes de él desde el punto de vista de su esencia y de su realidad, es decir, en el sentido de que no son sino pura agua. Las cosas existentes determinadas son del mismo modo diferentes del Absoluto por el hecho de que son condicionadas y determinadas pero no se distinguen de él en lo que respecta a su propia esencia y realidad, que es la existencia pura. Porque, desde este último punto de vista, no son más que la existencia misma». ${ }^{6}$

La aplicación que de esta metáfora hace el budismo nos llevará ahora a visitar otro de sus sistemas meditativos más importantes, denominado mahāmudrā o «gran símbolo». Declara un destacado texto de esta tradición: «De ese modo, la "práctica de la meditación” significa permanecer sin esfuerzo, a lo largo de los tres tiempos (pasado, presente y futuro), en el estado original e ilimitado de la mente tal como es. Tan sólo debemos reposar, sin controlar la respiración ni reprimir la mente, en dicho reconocimiento espontáneo con la alegre inocencia de un niño. Si emergen pensamientos y recuerdos, debemos permanecer en la presencia de nuestra propia naturaleza reconociendo que las olas no son distintas del océano». ${ }^{7}$ 
Uno de los principales métodos contemplativos de la escuela del mahāmudrā consiste en considerar los pensamientos como si fuesen lo que los budistas denominan el dharmakāya o «cuerpo de la realidad», es decir, la conciencia iluminada de un buddha. Si el dharmakāya es comparado al océano, los pensamientos y demás experiencias son similares a las olas que emergen en él. Pero, ya sea que el mar esté en calma o agitado, todas las olas son agua. Así pues, sin tratar de aquietar deliberadamente las olas mentales, evocamos la presencia del océano, que jamás se ve perturbado en sus profundidades sin importar el tamaño ni la cantidad de las olas que se produzcan en su superficie. De ese modo - nos asegura esta escuela meditativa-, los pensamientos se aquietan por sí solos de manera natural.

Y, abundando en las respectivas características de la mente en estado de quietud (el mar) y de la mente pensante o en movimiento (las olas), los maestros de esta tradición plantean cuestiones como las siguientes: ¿El movimiento de los pensamientos emergentes es diferente de la mente en estado de quietud? ¿Es la mente estable la que se mueve o es una parte de ella, como las olas y el océano? ¿Qué es aquello capaz de cobrar conciencia tanto de la estabilidad como del movimiento de la mente?8 Este tipo de indagación -que no es un mero ejercicio intelectual- prosigue más o menos por idénticos derroteros hasta que se obtiene una comprensión clara de la verdadera naturaleza de la experiencia.

Se enseña también que dicha naturaleza es como el océano, y el agua tranquila de sus profundidades la misma agua que la de sus olas turbulentas porque, de hecho, la substancia de la sabiduría iluminada es idéntica a la de la proliferación de pensamientos. ${ }^{9} \mathrm{El}$ agua en calma y el agua agitada por las olas - declara el gran maestro tibetano Longchenpa- son igualmente agua. Y, de manera similar, la mente que permanece en su lugar natural de reposo, más allá de los pensamientos, y la mente pensante, no son mejor o peor respectivamente, pues ninguna de ambas se aparta de su auténtica naturaleza.

Aunque la alegoría de las olas y el océano se centra, en el caso de la tradición meditativa budista, en la tarea eminentemente práctica de cómo abordar los pensamientos y el resto de experiencias durante el proceso de la meditación, nos transmite una relación muy similar de interdependencia entre el mar (naturaleza profunda de la mente) y las olas (pensamientos, sensaciones, emociones, experiencias, etcétera), que la referida por el sufismo cuando aplica la misma imagen a la polaridad de existencia pura y existencia condicionada, de realidad absoluta y relativa, o de Dios y su creación.

Y lo que ponen de relieve ambos enfoques es que, con independencia de la distinta interpretación que brindan de la misma alegoría, budismo y sufismo insisten en que interior y exterior, superficie y profundidad, quietud y movimiento, no-forma y forma, unidad y multiplicidad, se hallan siempre en continua comunicación, y que el sabio se ve obligado, por tanto, a vivir a la vez en dos mundos y a contemplar con doble mirada la realidad. Son imágenes que intentan, en suma, transmitirnos que ambos dominios mantienen una relación unitaria o no-dual. 


\section{LA LLAMA DE LA VELA}

El ejemplo de la combustión de la vela, sirve al budismo y al sufismo para exponer la tan aparente como falsa continuidad temporal de todos los fenómenos externos e internos. Escribe el gran sufí Hamadānī: «Los niños pequeños, al observar una lámpara arder de manera continua, piensan naturalmente que están viendo una sola llama. Pero los adultos saben muy bien que se trata de una serie de llamas diferentes que aparecen y desaparecen a cada instante. Y, desde el punto de vista de los místicos, este es el caso necesariamente de toda cosa en el mundo, salvo Dios». ${ }^{10}$ Por su parte, Ibn 'Arabī también recoge, en Las iluminaciones de La Meca, el símil del movimiento del fuego, el cual crea una ilusión de continuidad: «¿Acaso no ves la alegoría que te proporciona el veloz movimiento de las cosas? El observador concluye lo contrario de lo que el objeto realmente es, debido a que este se mueve con suma rapidez. Cuando su movimiento se acelera al girar, uno dice acerca del fuego en el rescoldo o en la punta de un palo, que "produce una línea continua" o "circula rápidamente", y ve en el aire un círculo de fuego. La razón de ello es la falta de estabilidad». ${ }^{11}$

Y, aludiendo también a la relación de los planos absoluto y relativo de la realidad, expresada a través de un punto de luz o una antorcha en movimiento, el sufi Mạ̣mūd Šabistarī (m. 1340) señala: «Es debido a nuestra imaginación, es decir, a la estructura del conocimiento humano, que todas las cosas nos parecen "distintas" (al Absoluto), igual que un punto que gira nos parece un círculo». ${ }^{12}$ Y comenta, por su parte, Toshihiko Izutsu que, cuando movemos a toda velocidad un tizón en la oscuridad, se crea la ilusión de un círculo de luz. El estado de unidad del Absoluto es parecido al punto de fuego y el mundo de la relatividad y la multiplicidad al círculo aparente creado por el movimiento de ese punto. El mundo fenoménico - concluye- no es sino la estela que deja tras de sí la actividad creadora del Absoluto. ${ }^{13}$

Con independencia de su movimiento, la imagen de la llama también es utilizada con frecuencia por la tradición budista para transmitir, en otro orden de cosas, la tan aparente como falsa continuidad temporal de nuestra existencia. Cuando observamos arder la llama de una vela, creemos que se trata de la misma llama ardiendo a cada momento pero, de hecho, está desapareciendo y reapareciendo a cada instante. Albergamos la ilusión de que sólo existe una llama debido a nuestra percepción errónea de la continuidad temporal, si bien no podemos afirmar que el oxígeno y los otros gases que hacen combustionar la llama en un determinado momento sean los mismos que la hacían arder hace un instante. Aunque la llama parece la misma que observábamos, no se trata, propiamente hablando, de la misma llama, y lo mismo ocurre con nuestra existencia. De hecho, aunque parecemos existir como una entidad sólida y estable en momentos sucesivos del tiempo, carecemos, según explica el budismo, de un yo inmutable. Como señala el importante comentarista budista Nāgasena, de cuyo célebre texto Preguntas al rey Milinda proceden los comentarios a esta metáfora, la llama de la vela depende del soporte y de los gases que la hacen entrar en combustión, y, de igual modo, la persona también depende, para su existencia, de la confluencia e interacción de diferentes factores y condiciones, sin que sea posible localizar un yo sólido y permanente más allá de dichas condiciones variables. 


\section{EL ESPEJO Y LOS REFLEJOS}

También es muy significativo el símil del espejo, utilizado por sistemas de meditación budista, como el Mahāmudrā, para exponer diversos aspectos de lo esta escuela meditativa denomina vacuidad, claridad y manifestación sin obstrucción, que constituyen, según dicha escuela, las características básicas de la realidad. Se afirma que la vacuidad -o el hecho de que los fenómenos externos e internos, incluido el yo, carezcan de una existencia sólida e independiente- es comparable a la limpidez y pureza fundamental del espejo, el cual no juzga los reflejos, más o menos agradables, que puedan proyectarse en él.

La mente, al igual que un espejo, es capaz de reflejar la imagen de cualquier objeto, apariencia o experiencia que se ubique cerca de ella, dado que la capacidad de reflejar es una función inherente al espejo. Los reflejos que se dibujan en el espejo no hacen sino manifestar visiblemente esta función reflexiva primordial. Según explican los maestros de esta tradición meditativa, aunque puedan emerger diferentes pensamientos y experiencias (los reflejos), la auténtica naturaleza de la mente (el espejo) no se ve modificada ni condicionada por ellos. La naturaleza profunda de la mente no juzga, sino que tan sólo se limita a reflejar, como la limpia superficie de un espejo, todas las experiencias que se proyectan en ella. Y, de igual modo que el espejo no cambia ni ve mermada su claridad o capacidad de reflejar a causa de las variadas apariencias que muestra su superficie, la verdadera naturaleza de la mente tampoco se ve modificada por las diversas experiencias, positivas o negativas, que pueda acoger.

Esos tres aspectos -la claridad y limpidez del espejo, su capacidad de reflejar y las imágenes que se reflejan en él- son indisociables, y todos ellos son fundamentales para que exista eso que llamamos espejo. Recordamos una vez más que las alegorías de la luz y su descomposición en los colores, del océano y las olas y del espejo y los reflejos se proponen mostrarnos la relación no-dual que mantienen los dominios absoluto y relativo de la realidad.

Ibn 'Arabī también hace un amplio uso, en diferentes contextos, de esta misma alegoría, si bien desde una óptica explicativa muy distinta. No obstante, parece producirse una cierta confluencia entre la perspectiva akbarí y la budista en lo que respecta a la peculiar situación cognoscitiva que procura un espejo porque, según explica el Šayh, y también los maestros de la tradición mahāmudrā, ver nuestra imagen proyectada en otro objeto - el agua, un espejo o cualquier superficie pulida- nos brinda un conocimiento específico de nosotros mismos inalcanzable por otros medios. Si no fuese por ese tipo de soporte, capaz de devolvernos nuestra propia imagen, no podríamos contemplarnos a nosotros mismos.

Declara el gran Šayh que es el deseo del Dios desconocido por darse a conocer y revelar el misterio de su tesoro infinito de nombres y cualidades el que le lleva a querer verse reflejado en un objeto inclusivo que abarque la totalidad de la existencia, «porque ver una cosa por sí misma - escribe- no es 
lo mismo que verla en otra cosa, como, por ejemplo, un espejo, pues esa visión opera entonces en la forma que le confiere el soporte de su mirada; sin la existencia de este soporte, no podría manifestarse ni aparecerse a sí misma». ${ }^{14}$ Este espejo es el llamado «ser humano perfecto», también conocido como microcosmos o «pequeño universo».

El yo no puede, dicho en términos psicológicos, verse a sí mismo si no es reflejándose en el otro. El conocedor sólo puede tratar de completar en lo conocido el conocimiento que tiene de sí mismo, pero nunca llegará a conocerse del todo porque el sujeto conocedor no puede convertirse en un objeto de conocimiento ni en objeto de ningún otro tipo. Dado que el yo, el sujeto, no puede transformarse en un objeto de experiencia, necesita un espejo que le restituya su imagen. Todas nuestras sensaciones, sentimientos, pensamientos - $-\mathrm{y}$, mucho más, nuestro entorno y las personas con las que nos relacionamos- son espejos que nos devuelven nuestro propio semblante proyectado sobre un flujo de fenómenos en extremo fugaces que nunca es idéntico a sí mismo y que se halla en constante transformación. Así pues, no podemos vernos directamente sin el auxilio de un intermediario. Lo único que nos es dado contemplar es nuestro reflejo proyectado en el espejo de los demás, en el espejo del mundo y, como precisaría Ibn 'Arabī, en el espejo de lo Real, que es Dios.

Nos dice además que el cosmos en su conjunto -o lo que en otras instancias denomina «gran ser humano»- es el espejo en el que se proyectan los nombres y atributos divinos o, si se prefiere, las cualidades de la existencia ilimitada. Pero, si el cosmos es para Allāh como el espejo en el que ve su forma, entonces, Él sólo se ve, se conoce y se ama a sí mismo, si bien proyectado en los espejos que, con grados distintos de limpidez y pureza, le proporciona la infinita variedad de sus criaturas.

Ilustra también con la misma alegoría la relación existente entre tres categorías ontológicas fundamentales en su cosmovisión, a saber: existencia absoluta, nada absoluta y posibilidad, definiendo a esta última como la imagen de la existencia reflejada en el espejo de la nada. La explicación ofrecida por el Šayh nos permite deducir que la imagen proyectada en el espejo - es decir, la categoría de lo posible- no es una nada completa (el espejo sin imagen alguna), ni tampoco existe verdaderamente (pues tan sólo es un reflejo). Y expresa en ese sentido: «La nada absoluta se presenta como si fuese un espejo al ser absoluto. Este ve su forma propia en aquella y esa forma es la esencia de lo posible. Por esto tiene lo posible esencia positiva y realidad en su mismo estado de no-ser; por esto, también aparece lo posible bajo la misma forma del ser absoluto; por esto, en fin, lo posible se define por la ilimitación, pudiendo decirse de él que es infinito. A su vez, el ser absoluto es un espejo para la nada absoluta. Esta se contempla a sí misma en ese espejo de la verdad y la forma que en él se ve es la esencia misma de la nada». ${ }^{15}$

El uso de esta metáfora también permite a Ibn 'Arabī dilucidar el mecanismo de las manifestaciones teofánicas, en un intento de evitar, en lo que concierne a la naturaleza de la realidad divina, las posiciones extremas del asociacionismo y el trascendentalismo o de la afirmación y la negación mutuamente excluyentes. En su opinión, la relación del cosmos con Dios es la misma que mantiene el 
reflejo mostrado en un espejo con el cuerpo que lo proyecta. Aunque pueda afirmarse que el cuerpo está en el espejo, obviamente no es así. Por otra parte, si bien la imagen reflejada no es el cuerpo que la proyecta - puesto que este es independiente del espejo-', tampoco es completamente distinta de él, ya que es su imagen, y no la de otro cuerpo, la que aparece en el espejo. De ese modo, si bien los seres no son Dios, tampoco podemos concluir que sean completamente distintos de Él. La afirmación y la negación no son contradictorias entre sí. El cosmos es y no es Dios al unísono.

Y destaca, insistiendo en el carácter ambivalente de las apariciones teofánicas -y entrando ahora en el terreno de la experiencia contemplativa profunda-, que la analogía del espejo es la más adecuada en este sentido porque transmite la advertencia, para el que recibe una revelación divina o contempla una manifestación teofánica, de que no albergue la idea equivocada de que ha visto realmente a Dios. Por eso expone: «Cuando te mires en un espejo, intenta ver también la superficie misma del espejo y comprobarás que te resulta imposible. En consecuencia, muchos concluyen que la imagen percibida está situada entre el espejo y el ojo del observador. Eso representa (de hecho) el máximo conocimiento de que son capaces (a ese respecto). Pero el asunto es tal como decimos nosotros y tal como ya lo hemos expuesto en Las iluminaciones de La Meca. Si lo has experimentado, habrás experimentado tanto como le es posible a un ser creado, de modo que no busques ni te inquietes por ir más allá porque más allá sólo existe el puro indiferenciado e inmanifestado (absoluto). Al contemplar tu autentico yo, Él es tu espejo y tú eres su espejo donde Él ve sus nombres y determinaciones, que no son otra cosa que Él mismo». ${ }^{16}$

En otras palabras, el viajero espiritual se esfuerza en llegar hasta su Señor pero, al final de su viaje, lo que se le revela no es sino su propia realidad y tan sólo contempla su propia imagen proyectada en el espejo de Dios. Podemos, en suma, contemplar nuestra forma reflejada en el espejo divino, pero no la superficie sobre la que dicha forma se proyecta. Dios es, desde la perspectiva akbarí, el medio a través del cual se produce nuestra comprensión, nuestro amor y nuestras acciones, pero es incognoscible en sí mismo y está más allá del amor, la acción o cualquier otra cualidad humana que pretendamos atribuirle.

Por otro lado, también cabe afirmar que la realidad es un juego de espejos y reflejos en el que todo es simultáneamente espejo y reflejo y en donde se mezclan las dimensiones interior y exterior, pues cuando dos espejos se hallan simétricamente enfrentados, el interior del uno se proyecta en el exterior del otro y viceversa. Es lo que expone precisamente Ibn 'Arabī al declarar que el exterior de Dios es el interior del ser humano, y el exterior de este, el interior de Dios; o, si se prefiere, que la aparición de Dios supone la ocultación del ser humano, mientras que la manifestación del ser humano -o el yo- conlleva la ocultación de Dios.

Abundando en lo anterior, si bien Dios y el ser humano son espejos que reproducen dentro de sí mismos la imagen del otro, también explica que en nuestra situación actual tal reflejo se halla invertido, y que, sólo después de la muerte, la imagen reflejada dejará de padecer los efectos de dicha 
inversión, pasando entonces lo visible a ser invisible y lo oculto a mostrarse de manera evidente: «En ese sentido - expone- el ser humano es como un espejo corriente: cuando alzas tu mano derecha al contemplar tu figura en el espejo, tu figura alza su mano izquierda. Por lo tanto, tu mano derecha es su mano izquierda y tu mano izquierda es su mano derecha. De aquí, oh criatura, que tu dimensión manifiesta sea la forma de Su nombre el No-Manifiesto, mientras que tu dimensión no-manifiesta es Su nombre el Manifiesto». ${ }^{17}$

Con el fin de resolver la aparente paradoja entre la unidad de la existencia y la multiplicidad de los seres, el Šayh nos pide que imaginemos una sola imagen proyectada en diferentes espejos. Los espejos múltiples representan, en este caso, la totalidad de los seres contingentes, en los que se plasma, de acuerdo a sus diversas características y capacidades para reflejarla, la manifestación de Dios o la luz de la existencia ilimitada.

De nuevo Haydar Āmolī pone el ejemplo de una vela reflejada en múltiples espejos para explicar este particular. En su libro El texto de los textos señala: «Por tanto, es importante tener simultáneamente la visión del Ser divino con la visión de las criaturas, y la visión de las criaturas con la del Ser divino. En resumen, es importante ver lo múltiple en la unidad [...] (y ver la unidad en la multiplicidad)». «La visión de la unidad en la multiplicidad y de esta en la unidad no es verdaderamente comprendida más que por la imagen de un espejo único en el que hay un cirio colocado en el centro. Alrededor hay múltiples espejos, de manera que en cada espejo aparece un cirio según la posición de cada espejo [...] Quien, en efecto, contemple el espejo único colocado en el centro y los espejos múltiples alrededor, contempla en cada uno de esos espejos un mismo cirio, de tal manera que, sin embargo, ese cirio único es cada vez otro cirio».

Y explica Henry Corbin, que es quien cita este pasaje en su libro La paradoja del monoteísmo: «Quien diferencia sin más ve los espejos, pero no ve el cirio único que está en el centro. Es el caso de la mayoría de los hombres. Quien integra sin más, no hace más que romper todos los espejos. No ve más que el cirio único en el centro. Es el caso del monoteísmo exotérico». En cambio, el monoteísmo esotérico, el teomonismo, consiste en «ver todos los espejos diferenciados al mismo tiempo que se ve el cirio en el centro».

Por otro lado, la aseveración, propia de la escuela akbarí, de que no hay nada en la existencia salvo Dios equivale a sostener que no hay, de hecho, nada en los espejos salvo aquel que se proyecta en ellos. Es cierto que las características, posición e impurezas de los distintos espejos pueden distorsionar la imagen proyectada, pero el que se contempla sigue siendo tal como es y no experimenta variación alguna. La multiplicidad no afecta a la unidad de la imagen original, sino que es el mismo rostro ${ }^{-o}$ el mismo cirio siguiendo con el ejemplo de Haydar Āmolī- el que se refleja en espejos que poseen grados variables de claridad y pureza. E insiste, respecto de las características de cada espejo, que, si bien la superficie del espejo es imperceptible, influye en las formas que asumen los reflejos proyectados en ella. Por eso proclama: «iGloria a Él, que sobrepasa todas las comparaciones y hace que las entidades 
aparezcan de manera que signifiquen que nada Le es similar y que Él no es similar a nada! No hay nada en el wuğūd sino Él, y el wuğūd sólo se recibe de Él. No se manifiesta ninguna entidad si no es a través de Su autorrevelación. Así pues, el espejo es la Presencia de la Posibilidad, lo Real es lo que aparece en él, y la forma somos nosotros de acuerdo con el modo de nuestra posibilidad, pudiendo ser un ángel, una esfera celeste, un ser humano o un caballo. Pero, al igual que la forma proyectada en un espejo, estamos supeditados a la apariencia de la propia esencia de cada espejo en términos de altura, anchura, circularidad y configuraciones diversas, si bien se trata de un espejo en todos los casos. Asimismo, las cosas posibles son como formas en la posibilidad. Cuando la autorrevelación divina imparte el wuğūd a las cosas posibles y el espejo les imprime formas diversas, se manifiestan el ángel, la sustancia, el cuerpo y el accidente, pero la posibilidad permanece invariable y nunca abandona su realidad». ${ }^{18}$

Y también aborda la cuestión de la diversidad de las creencias como las variaciones producidas, en una misma realidad, por las cualidades de cada espejo particular: «La esencia es como un espejo, de manera que el observador ve en ella la forma de su propia creencia acerca de Dios. Entonces la reconoce y la confirma [...] El espejo es único, pero las formas que revela son diversas a los ojos del espectador. Aunque ninguna de esas formas reside en el espejo, el espejo produce, de un modo u otro, un efecto sobre ellas. Puede hacer, por ejemplo, que la forma parezca más pequeña, más delgada, más alta o más ancha. Así, tiene un efecto sobre sus proporciones, que es atribuido a aquella, aunque esos cambios se deben tan sólo a las diferentes proporciones de los espejos». ${ }^{19}$

El fin último de la creación -nos enseña el sufismo- consiste en llegar a testificar la presencia de Dios, lo Real, tanto en el exterior como en nuestro interior a través del conocimiento del cosmos y de nuestro propio yo. El cosmos y el yo, o el gran ser humano y el pequeño universo - como los denomina el Šayh-, conforman un mismo espejo. El gran maestro andalusí compara la situación original del cosmos, antes de la creación del ser humano, con un espejo sin pulir que, no contando con la suficiente claridad - y en ausencia de la debida autoconciencia- es incapaz de reflejar adecuadamente la totalidad de los nombres divinos. El cosmos es el espejo de la belleza de Dios pero, mientras la conciencia humana no aporte a dicho espejo la claridad necesaria, sólo puede mostrarla de manera borrosa e imperfecta. Y señala en este sentido el gran Šayh que «el ser humano constituye el pulido del espejo opaco de la creación». ${ }^{20} \mathrm{El}$ principal cometido del ser humano reside, pues, en el pulido del espejo cósmico, ya que, al obrar de ese modo, no sólo cumplirá la función que le corresponde en el cosmos, sino que también realizará plenamente su humanidad.

Cuando se habla del espejo del cosmos y del esplendor y precisión aportados a él por la humanidad, hay que tener en cuenta el lugar privilegiado que ocupa el corazón en la constitución interna del ser humano, porque el corazón -continúa diciendo el Šayh- también es un espejo «con una cara totalmente incorruptible» ${ }^{21}$ que se halla en permanente comunicación con Dios. La tarea del hombre y la mujer de sabiduría, tanto el contexto del budismo como del sufismo, reside en el pulido del espejo 
del corazón o de la mente, respectivamente, el cual permite, en el primer caso, percibir la verdadera naturaleza de los fenómenos -o lo que los budistas denominan la unión de vacuidad y claridad-y, en el segundo, conocer el cosmos, conocernos a nosotros mismos y conocer a Dios. De ese modo, el ser humano se convierte en el espejo en el que Dios se percibe a sí mismo; vaciándose de su propio yo, es capaz de devolver a Dios su propio reflejo.

Retomando, ya para concluir, la relación indisociable que existe entre unidad y multiplicidad, entre realidad absoluta y realidad relativa, entre Dios y su creación, expuesta a través de las imágenes de la descomposición del rayo de luz en los colores del espectro, del océano y las olas y del movimiento del fuego, una de las principales lecciones que podemos extraer de la alegoría del espejo, es que el espejo y los reflejos no se tocan de hecho, si bien las propiedades de los diferentes espejos modifican las imágenes que aparecen en ellos. Y también las características de la realidad relativa y la esfera de la multiplicidad condicionan el modo en que se manifiesta la realidad absoluta y el dominio de la unidad, pues la visión siempre se produce -como escribe el gran maestro andalusí- en la forma que le confiere el soporte de la mirada, y el agua de la revelación teofánica siempre adopta la configuración del receptor que la acoge.

1 Ralph Metzner, Las grandes metáforas de la tradición sagrada. La transformación de la conciencia y la naturaleza humana, Editorial Kairós S.A., Barcelona, 1988, págs. 9-10.

2 Chittick, William C., Mundos imaginales: Ibn al-Arabīy la diversidad de las creencias, Mandala Ediciones, Sevilla, 2010, pág. 32.

3 Ibid., pág. 34 .

4 (Fut. IV, 202.6) Ibid., pág. 35.

5 Izutsu, Toshihiko, Unicité de l'Existence et Création Perpétuelle en Mystique Islamique, Les Deux Océans, París, 1980, pág. 80

6 Ibid., págs. 43-44.

7 http://yoganatural.blogspot.com.es/search/label/C\%C3\%81NTICO\%20DEL\%20MAHAMUDRA $\% 20$

$\% 28$ SARAHA $\% 29$

8 Trois Enseignements par Kalou Rinpoche, Editions Yiga Tche Dzim, s.f., pág. 43.

9 Baroetto, Giuseppe, Mahamudra y Atiyoga, D.K. Printworld, diciembre, Nueva Delhi (India), 2005, pág. 92.

10 Izutsu, Toshihiko, op. cit., pág. 115.

11 Futūhāt al-makkiyya (The Openings in Makkah) Ibn-al-Arabī. Cosmography: Writing the Universe (traducción de Eric Winkel), Edición provisional, Amazon, 2016, pág. 79.

12 Izutsu, Toshihiko, Ibid., pág. 40.

13 Ibid., pág. 42.

14 Fusūs al-hikam. The Bezels of Wisdom (traducción inglesa de R.W.J. Austin), Nueva Jersey, Paulist Press, 1980, pág. 91. 
15 Cruz Hernández, Miguel, Historia del pensamiento en el mundo islámico: (II) El pensamiento de al-Ándalus (siglos ixxiv), Alianza Editorial, Madrid, 2000, pág. 258.

16 The Bezels of Wisdom, pág. 65.

17 (Fut. IV 135.33) Chittick, William C., Mundos imaginales: Ibn Arabiy la diversidad de las creencias, pág. 198.

18 (Fut., III 80.14) Chittick, William C., The Self-Disclosure of God, pág. 16

19 The Bezels of Wisdom, pág. 65.

20 Ibid., pág. 90.

21 (Fut. I, pág. 91), Addas, Claude, Ibn Arabî et le voyage sans retour, Éditions du Seuil, París, 1996, pág. 99. 